\title{
Para além da escrita hagiográfica: biografias católicas e cultura histórica no Brasil em fins do século XIX e início do $\mathrm{XX}^{*}$
}

\author{
Beyond the hagiographic writing: Catholic biographies and historical \\ culture in Brazil in the late nineteenth century and early twentieth
}

\author{
Tiago Pires \\ tiago_pires@ymail.com \\ Doutorando em História \\ Universidade Estadual de Campinas \\ Avenida Catanduva, 458 - Jardim América \\ 14811-220 - Araraquara - São Paulo \\ Brasil
}

\begin{abstract}
Resumo
A Igreja Católica em fins do século XIX e início do XX estava envolvida em diferentes projetos teológico-políticos de reforma e fortalecimento da identidade institucional. A escrita eclesiástica tornou-se uma ferramenta privilegiada para a concretização de tais projetos, sendo as biografias católicas uma das modalidades mais utilizadas. Neste artigo, pretendemos analisar algumas biografias católicas no Brasil, redigidas no âmbito da Arquidiocese de Mariana, buscando compreender de que forma esse estilo narrativo foi constituído como um projeto de fortalecimento da memória e da identidade institucional e sacerdotal, em diálogo com os enunciados e enunciações

214 das hagio-biografias e da cultura historiográfica brasileira da época.
\end{abstract}

Palavras-chave

Biografia; Catolicismo; Historiografia brasileira

\section{Abstract}

The Catholic Church in the late nineteenth century and early twentieth century was involved in different theological-political projects of reform and strengthening of the institutional identity. Ecclesiastical writing has become a privileged tool for the achievement of these projects, and the Catholic biographies were one of the most used modalities. This article aims to analyze some Catholic biographies in Brazil, written in the Archdiocese of Mariana, trying to understand how this narrative style was established as a project to strengthen the memory and the institutional and sacerdotal identity, in a dialog with the contents and enunciations of hagio-biographies and Brazilian historiographical culture from that time.

Keywords

Biography; Catholicism; Brazilian historiography.

Recebido em: 6/6/2016

Aprovado em: 11/11/2016

\footnotetext{
* Este artigo é uma versão revisada e modificada de parte da minha dissertação de mestrado, com pesquisa financiada pela Fundação de Amparo à Pesquisa do Estado de São Paulo (Fapesp).
} 
Em fins do século XIX e início do XX, a Igreja Católica, em sua multiplicidade de discursos e posicionamentos, manteve uma linha relativamente comum: a de promover uma unificação cada vez mais intensa sob a ótica de um catolicismo ultramontano, ou seja, de uma religiosidade ainda muito vinculada ao modelo tridentino e à obediência papal. O catolicismo contemporâneo deve ser pensado como plural (por isso o uso cada vez mais constante do termo "catolicismos"), ainda que o clero mais ligado à Santa Sé e aos altos cargos da instituição busque uma identidade mais unificada, pelo menos no recorte temporal que propomos analisar. O discurso eclesiástico anterior ao Concílio Vaticano II (19621965) pautava-se muito na ideia de uma Igreja centralizada que buscava uma identidade comum. Uma análise histórica cuidadosa logo nos revela que isso não passava de um discurso, já que a vivência religiosa (do clero e dos fiéis) se ramificava em vários momentos.

Em meio às diferentes estratégias de fortalecimento da instituição, a escrita eclesiástica assumiu um papel privilegiado na construção de modelos exemplares de sacerdotes e de igreja. As diferentes modalidades narrativas estavam longe de representar a fé daquela época. Alguns tipos narrativos, como as biografias e autobiografias, constituíam-se como uma prática discursiva em que a fé era criada/remodelada a partir dos diferentes projetos políticos. Por isso a necessidade de entendê-las não como retratações de um suposto "real", mas como práticas formadoras de sentido (CERTEAU 1998, p. 278).

As biografias católicas de fins do século XIX e da primeira metade do XX se aproximaram do modelo das hagiobiografias, ${ }^{1}$ sobretudo do estilo narrativo da obra de Francis Trochu (PIRES 2014). Nem sempre elas relatavam a vida de sacerdotes ou bispos com fama de santo, mas certamente descreviam trajetórias exemplares, principalmente daqueles padres ligados ao modelo romano e ultramontano. Na tentativa de legitimar seus enunciados, mantiveram um diálogo com a cultura histórica desse contexto. As biografias eclesiásticas de fins do século XIX e início do XX se apropriaram de alguns elementos da historiografia brasileira que circulavam nessa conjuntura, perpassando pelas concepções históricas e narrativas das biografias do Instituto Histórico e Geográfico Brasileiro e mesmo da historiografia do início do século XX.

Neste artigo, o nosso interesse é entender de que maneira tais narrativas se apropriaram da cultura historiográfica brasileira da época para construir e legitimar os diferentes projetos religiosos e teológico-políticos da instituição e de seus membros. Dessa forma, não nos prolongaremos nas definições de hagiobiografia e das biografias laicas modernas, já realizadas em outros trabalhos (PIRES 2013).

\footnotetext{
${ }^{1}$ As hagio-biografias foram muito comuns durante o século XIX e início do XX. Abarcavam um estilo narrativo híbrido, que transitava entre as biografias laicas modernas, nos moldes das Confissões de Rousseau, e as tradicionais hagiografias. Não eram exclusivamente vidas de santos e nem biografias laicas. Havia, portanto, uma dificuldade em definir, no mundo católico, o que era biografia e hagiografia. Para um estudo mais aprofundado, conferir as definições presentes em Pires (2013).
} 


\section{Biografias católicas no Brasil}

Diferentemente das autobiografias, as biografias católicas foram mais recorrentes nesse recorte. Devido à pluralidade das obras biográficas eclesiásticas do período, recortamos como material de análise a do monsenhor José Silvério Horta e a dos bispos marianenses D. Viçoso (1787-1875) e D. Silvério (18401922) (HORTA 1934; PIMENTA 1920; SOUZA 1927). A biografia de José Silvério Horta foi escrita por seu sobrinho Francisco Horta. O arcebispo de Mariana, D. Silvério Gomes Pimenta, escreveu a vida de seu mestre D. Viçoso, e o primeiro arcebispo de Diamantina, D. Joaquim Silvério de Souza, escreveu uma das biografias sobre $D$. Silvério. ${ }^{2}$ Os biografados foram eclesiásticos que atuaram na Arquidiocese de Mariana, bem como os biógrafos, com exceção do arcebispo de Diamantina. Prática comum, como poderemos notar, não só nas arquidioceses mineiras do período.

Em um breve levantamento das biografias católicas de fins do século XIX e da primeira metade do $\mathrm{XX}$, conseguimos identificar um número significativo de obras, como: Dom Epaminondas (1941), escrita pelo padre Ascânio Brandão; Dom Joaquim, $1^{\circ}$ Arcebispo de Diamantina (1935), do padre Celso de Carvalho; D. Vital (1932), de Perilo Gomes; D. Joaquim Mamede da Silva Leite (1941) e Elogio histórico de d. João Nery, 10 bispo de Campinas (1945), de José Carlos de Ataliba Nogueira; Traços biográficos de Dom Silvério Gomes Pimenta (1941), do monsenhor Alípio Odier de Oliveira; Um grande brasileiro: D. frei Vital Maria Gonçalves de Oliveira, bispo de Olinda (2a ed., 1936), do frei Feliz de Olivola;

216 D. José Gaspar: biografia-depoimento (1944), de Tavares Pinhão; O bispo de Olinda perante a história (D. frei Vital M. Gonçalves de Oliveira, dos meninos capuchinhos) (1878), de Antônio Manuel dos Reis; D. Duarte Leopoldo e Silva, arcebispo de São Paulo: esboço biográfico, homenagem do clero e dos católicos da arquidiocese, por ocasião do jubileu de sua sagração episcopal - 1894/1929 (1929), de Júlio Rodrigues; Júlio Maria (1924), de Jonathas Serrano; Frei Rogério Neuhaus (1934), do frei Pedro Sinzig (MICELI 2009, p. 187-191). Como se percebe, a construção das biografias do clero exemplar foi feita, em grande parte, por religiosos, mas algumas também por intelectuais renomados, como o professor de História do colégio D. Pedro II e membro do IHGB, Jonathas Serrano (1855-1944).

Tais biografias não eram escritas de forma aleatória. De acordo com Sergio Miceli (2009, p. 39), "alguns bispos preferiam redigir biografias circunstanciadas de seus patronos quando o status reconhecido de líderes de que desfrutavam os biografados era de molde a justificar um trabalho hagiográfico", ou quando ganhavam destaque pastoral nas dioceses. Esse era o caso de monsenhor Horta e de D. Viçoso, ambos com fama de santidade e iniciados posteriormente no processo de canonização. Outra modalidade comum eram as histórias eclesiásticas, que, fazendo pequenos traços biográficos do clero, apresentavam uma leitura apologética e de reafirmação da Igreja diante da sociedade brasileira

\footnotetext{
2 Mapeamos algumas outras obras de perfil biográfico sobre D. Silvério, como $O$ arcebispo negro: ensaio de uma síntese da vida e obra de D. Silvério Gomes Pimenta (1942), de Benedito Ortiz, e Traços biográficos de D. Silvério Gomes Pimenta (1940), do monsenhor Alípio Odier de Oliveira.
} 
(PIRES 2010, p. 5). Trata-se de um conjunto de biografias "produzidas com intenções edificantes, com frequência a versão oficiosa encomendada pela hierarquia a respeito de acontecimentos que deram margem a interpretações e as posições de facções do clero, ou de comprometer a imagem pública da organização" (MICELI 2009, p. 45). Além disso, a construção e difusão de modelos exemplares por meio de biografias era parte de um projeto reformista e político, voltado para a reafirmação da fé e do poder da Igreja Católica na sociedade brasileira, sobretudo a partir da Primeira República.

Ainda segundo Miceli, os modelos dessas narrativas biográficas foram homogêneos, aproximando-se do estilo das vidas dos santos, relatando a vida de eclesiásticos exemplares, prestadores de serviço à hierarquia católica de suas dioceses (MICELI 2009, p. 44). No entanto, podia acontecer que esses padres e suas narrativas não estivessem de acordo com o que a hierarquia eclesiástica almejava, tornando tal relação mais complexa e tensional. A postura e as biografias sobre certos padres milagreiros, como o padre Eustáquio Van Lieshout (1890-1943), ${ }^{3}$ vigário de Poá, incomodavam alguns superiores católicos. Suas práticas de cura, interpretadas como sobre-humanas, muitas vezes eram associadas ao espiritismo ou à supersticiosidade do povo, aspectos para os quais a Igreja olhava com certa desconfiança. Lieshout foi afastado da diocese por tais questões, vindo a falecer em 1943. Mas, nem sempre a situação foi semelhante.

A biografia de monsenhor Horta, escrita por seu sobrinho Francisco Horta, está repleta de casos interpretados por ele como de ordem sobre-humana, o que chamou a atenção de outros grupos religiosos. Sabendo que era apreciado por círculos espíritas de Minas Gerais, monsenhor Horta fez questão de relatar em seus escritos os perigos da participação em tais reuniões (HORTA 1932, p. 26; HORTA 1939, p. 15-17), além de estar em ampla afinidade com as concepções teológicas e religiosas da Arquidiocese de Mariana. Consciente dessa associação com outras religiões, ele alertava de várias formas o seu não envolvimento, e mesmo sua reprovação, com as práticas mediúnicas que ganharam notoriedade no Brasil em fins do século XIX e início do XX (LEWGOY 2008, p. 86-87). Talvez tal fato tenha feito com que Horta e seus escritos, inclusive sua biografia, fossem mais apreciados pela hierarquia da Arquidiocese, algo que não ocorreu com as práticas e escritos sobre o padre Lieshout.

Nem sempre as biografias atendiam às demandas da hierarquia clerical, apesar desse cumprimento ser uma condição fundamental para a aprovação e para o projeto de escrita de muitas obras do gênero. Fazendo uso de um modelo de erudição histórica, pautada no uso abundante de documentação primária (cartas, sermões, autobiografias, testemunhos), os biógrafos traçavam a vida de seus coirmãos em um viés apologético e memorialista, porém menos romanceado e se apropriando de elementos da cultura histórica do contexto. Contudo, as biografias como obras de edificação não se restringiram ao âmbito

\footnotetext{
3 O padre Van Lieshout nasceu em Aarle-Rixtel, Holanda, e faleceu em Belo Horizonte em 30 de agosto de 1943. Membro da Congregação dos Sagrados Corações, sua biografia foi publicada em 1944, escrita pelo padre Venancio Hulselmans, da mesma congregação.
} 
religioso. Como nota Dosse (2009, p. 61), "em meados do século XIX, o modelo de [James] Boswell cede o passo ao domínio absoluto do que chamamos de biografia vitoriana, submetida a fortes coações moralizadoras. Obra de edificação, a biografia dessa época se confunde com a hagiografia".

As biografias católicas foram, enfim, variadas: "histórias de vida de figuras eminentes da corporação eclesiástica, líderes, missionários, místicos, educadores, milagreiros e santos, com participação destacada nos principais acontecimentos religiosos e políticos da época". Havia também os perfis de prelados e "as chamadas 'polianteias', ${ }^{4}$ editadas em homenagem a diversos membros graduados do episcopado" (MICELI 2009, p. 43-44). As biografias que analisamos, entretanto, estavam para além do modelo hagiográfico.

\section{Para além da escrita hagiográfica: um diálogo com as biografias históricas}

A fim de legitimar a autenticidade da escrita biográfica eclesiástica, seus autores optaram por dialogar com a economia de verdade presente na cultura histórica de seu contexto. Afinal, diante de uma sociedade em processo de laicização e da cultura histórica circulante, era preciso mais que um texto poético ou romanceado para difundir os modelos de sacerdotes exemplares, virtuosos e em alto grau de santidade, protótipos esses não tão comuns na cultura clerical nacional (OLIVEIRA 2010). Dessa forma, foi necessário elaborar e projetar uma identidade clerical para o Brasil, além de perpetuar a memória e a gratidão a esses eclesiásticos que ganharam fama em suas dioceses como missionários e 218 pastores de almas de destaque (PIMENTA 1920, p. VI):
A história vem pois derramar estes benefícios, e estendê-los a um círculo muito largo. Se não fora sua valiosa coadjuvação, os bens do exemplo ficariam restringidos aos que tivessem a dita de os presenciar por si mesmos, ou os ouvissem destas testemunhas imediatas (PIMENTA 1920 , p. V).
[...] com quantas dificuldades lutamos para não serem muitas as inexatidões nesta biografia bem o podem atestar os que com documentos e informações contribuíram para a escrevermos (SOUZA 1927, p. 7).

Uma das primeiras obras religiosas de perfil biográfico nas Minas oitocentistas foi a do prelado Dom Viçoso, escrita pelo futuro bispo da Arquidiocese de Mariana, Silvério Gomes Pimenta. A primeira edição foi publicada em 1876, abarcando, como diz o autor na introdução, um repertório dedicado aos futuros historiadores mineiros (PIMENTA 1920, p. III). A narrativa entrelaça à vida e à doutrina de Viçoso a história do desenvolvimento de Minas, apresentando suas virtudes, trajetória pessoal e, principalmente, sua atuação e formação religiosa. Uma escrita exemplar, a serviço da edificação e imitação dos padres e fiéis da Pátria. "Nutrimos esperanças que os Mineiros, há pouco sôfregos em escutar

\footnotetext{
${ }^{4}$ As polianteias "constituem um gênero extremado de apologia organizacional, concedendo aos prelados assim homenageados um tratamento honorífico idêntico àquele de que já desfrutavam as sumidades do episcopado europeu". Eram obras editadas em ocasiões especiais ou encomendadas pelo interessado (MICELI 2009, p. 53).
} 
a voz de seu Pastor, e que se apinhavam em derredor dele nas cidades, nas vilas, nos arraias, e até nas fazendas" (PIMENTA 1920, p. VI). Próximo do povo, porém não milagreiro, o bispo incorporou um perfil de santidade já circulante no século XIX, menos "sobre-humano" e mais afeito às virtudes psicológicas e morais (ROSA 2000; VAUCHEZ 1987, p. 289). Sua biografia também ressaltou essa perspectiva:

[...] não dará no gosto de certos leitores, que mais buscam regalar a imaginação com espetáculo curioso, ainda que falsos, do que nutrir o entendimento e o coração com a narração de virtudes simples e comuns, as quais, se não tem o brilho do relâmpago, tem os encantos e suavidade da luz da autora, e os doces atrativos da verdura dos campos [...].

Não procures, leitor, nesta biografia esses rasgos extraordinários, e atos estupendos, com que Deus favorece alguns de seus santos, outra foi a missão de $D$. Antonio: ensinar com a palavra e com o exemplo as virtudes que todos podem imitar, e mostrar que um gênero de vida, ao parecer, tão vulgar e singela, se podem encerrar preciosos tesouros de santidade peregrina (PIMENTA 1920, p. VII).

A biografia de Viçoso tornou-se um modelo narrativo na Arquidiocese de Mariana para as futuras publicações desse perfil. A Vida de D. Silvério Gomes Pimenta (1927), redigida pelo bispo de Diamantina, D. Joaquim Silvério de Souza, cita a biografia de Viçoso e adota, inclusive, o mesmo estilo narrativo. As obras são repletas de citações e até referências, sendo estruturadas em diversos pequenos capítulos que vão da infância à atuação eclesiástica. A parte religiosa ocupa um espaço central, mas as vivências cotidianas, tais como as angústias e tensões do vivido, não são ocultadas da narrativa. Apesar de adotar um modelo temporal cronológico, a narrativa não constrói uma personagem totalmente solidificada e unificada durante a vida. As variações identitárias e as narrações de aspectos cotidianos do biografado não excluem a construção de suas virtudes, características essas que apresentam o diálogo da biografia católica com as biografias laicas modernas.

Tais biografias também dialogaram com o modelo das hagiografias, sobretudo porque os biografados e os biógrafos eram assíduos leitores das vidas dos santos e, dessa forma, se apropriaram da maneira de escrever e das virtudes e tópicas hagiográficas. A vida do biografado é significada em Deus, sendo ele um eleito da vontade divina: "Não eleva Deus algumas almas privilegiadas e tão levantados graus de santidade só por amor deles, senão para que sirvam de archote aos que vivem nas trevas deste mundo, e de guias seguros no caminho da virtude" (PIMENTA 1920, p. V). Nesse sentido, a biografia dialoga com a vida dos santos, porém sem necessariamente abarcar uma dimensão teofânica da temporalidade, na qual o tempo só revela o que já foi dado no início sagrado da existência do biografado. Além disso, muitos deles presenciavam em vida, ou no final da existência, o reconhecimento da sua santidade, sendo a escrita biográfica um dos meios de construir e legitimar a vida do "santo". Esse foi o caso de monsenhor Horta, por exemplo. 
A Vida de D. Silvério Gomes Pimenta apresenta variados capítulos que concatenam algumas de suas virtudes, as quais, por sinal, aproximam-se do modelo de pastor das almas também representado por D. Viçoso e monsenhor Horta: humildade, paciência, suavidade, caridade, respeito ao papa e aos superiores. Dom Silvério, próximo do povo e virtuoso, porém não milagroso, pregava com a superioridade do coração:

[...] vendo-o viver no meio deles, mais simples e operoso que eles, interessando-se por sua saúde, subsistência e sua alma, verificará quão sólida e vasta é a autoridade de quem governa pela superioridade do coração. [...]

Seguindo-o nas penosas e contínuas viagens, empreendidas dentro e fora do país, a bem de suas ovelhas, lendo suas evangélicas instruções, que não raro citaremos, contemplará o leitor um sacerdote fiel, um varão apostólico, por Deus suscitado para despertar energias, excitar santas emulações no serviço da salvação das almas (SOUZA 1927, p. 6-7).

Envolto em amplos debates políticos, articulados pelos seus pronunciamentos nas pastorais e nos jornais católicos, Silvério chegou a ser acusado de simonia. Sua biografia serviu também para resolver essa e outras polêmicas em que se envolveu, algo comum nas (auto)biografias laicas (CALLIGARIS 1998, p. 43). A Vida de D. Silvério Gomes Pimenta apresenta uma característica comum às biografias católicas: sua sujeição à hierarquia eclesiástica e aos modelos de santidade e virtudes que almejavam construir e propagar.

Protestando inteira obediência às leis da Igreja, reprovamos o que ela julgue neste escrito digno de censura, e declaramos não desejar nos antecipar ao juízo dela, se neste escrito alguma expressão que significa santidade nos sai da pena ao nos referirmos a $D$. Silvério ou a outrem (SOUZA 1927, p. 8).

As biografias católicas desse período almejavam construir as histórias "verdadeiras" dos prelados exemplares ou dos possíveis candidatos à santidade, utilizando com abundância a documentação primária e entrevistas com pessoas que haviam convivido com o biografado. "Consultamos as pessoas que lograram mais intimidade com o nosso Prelado, pedimos-lhes informações minuciosas de quantos sabiam, e estudamos escrupulosamente os documentos [...]" (PIMENTA 1920, p. VIII). Silvério Pimenta pede desculpas pelas faltas e lacunas da obra, mas expressa na introdução seu desejo de buscar a "verdade" e ser o mais fiel possível à vida de D. Viçoso. Pautadas em um método histórico crítico e no uso abundante de fontes na busca pela "verdade" e "imparcialidade", as biografias católicas de fins do XIX e início do XX nos mostram um diálogo com alguns dos princípios da cultura histórica desse mesmo contexto a fim de legitimar um projeto teológico-político, indo além, portanto, do estilo hagiográfico e biográfico.

Narrar a vida de personagens ilustres e exemplares não se restringia ao âmbito religioso. Uma seção específica da Revista Trimestral do Instituto Histórico e Geográfico Brasileiro foi criada em julho de 1839 sob o título de 
Biographia dos Brasileiros Distinctos por Lettras, Armas, Virtudes, Etc. Até 1899, foram contabilizados aí 154 trabalhos "sob a rubrica de biografia ou apontamentos biográficos" (OLIVEIRA 2007, p. 154). Tais narrativas estão entrelaçadas na consolidação do discurso historiográfico oitocentista no Brasil, empreendido pelo IHGB em meados da segunda metade do século XIX, com vistas à institucionalização da história como discurso dotado de regras próprias de elaboração e validação. Como se deve escrever a história da nação? Inicialmente, a veiculação da vida de personagens escolhidos como ilustres proporcionava a construção não só de um tipo de narrativa, mas de um modelo de nação que buscava no passado elementos para a sua consolidação no presente e sua orientação para o futuro. ${ }^{5} \mathrm{O}$ projeto historiográfico das biografias, que incorporou os métodos históricos disponíveis, baseava-se na fórmula da história mestra da vida, perdurando até o fim do século XIX, quando, não por acaso, as biografias do IHGB começaram a desaparecer (OLIVEIRA 2007, p. 157). O abandono do gênero biográfico a partir de 1880 está relacionado à mudança do projeto historiográfico do instituto, não mais pautado na história magistra vitae.

A escrita da história nacional na segunda metade do século XIX incorporou as premissas de um regime historiográfico com pretensões científicas na elaboração de biografias de personalidades ilustres da história do Brasil. A partir de tais indivíduos, a narrativa histórica corroborava para a consolidação de um dos projetos políticos e historiográficos do IHGB, voltado para a elaboração de modelos e exemplos que representassem o Brasil e sua identidade (OLIVEIRA 2010a, p. 39). Para tanto, a prática historiográfica fez uso abundante de fontes e de um olhar metodológico rigoroso, "imparcial", em busca de um passado factual e verdadeiro (CEZAR 2003, p. 78). Tais noções aparecem com clareza nas biografias eclesiásticas que mencionamos anteriormente, apesar de sabermos que tal rigor não se desdobrava em objetividade e imparcialidade total.

Em todas as biografias católicas que analisamos, a introdução das obras apresenta uma proposta de escrever a história verdadeira do sacerdote, mais fiel possível à sua vivência. Utilizam-se fontes em diferentes modalidades e uma "imparcialidade" que garante ao trabalho, na visão de seus autores, um tom objetivo e histórico. Para reafirmar tais proposições, alguns autores, como o biógrafo do monsenhor Horta, definem que a obra não se trata de um texto literário, mas de uma apresentação da vida do padre José Silvério Horta. Na Vida de D. Antonio Ferreira Viçoso (1876), as pretensões em escrever um texto com valor histórico e destinado aos historiadores aparecem logo na introdução (PIMENTA 1920, p. III). Talvez essa diferenciação entre texto histórico e literário seja algo mais específico das biografias católicas da primeira metade do século $\mathrm{XX}$, haja vista que:

\footnotetext{
${ }^{5}$ Algumas personagens religiosas também apareciam na seção de biografias do IHGB, ganhando um espaço considerável. Contudo, "grande parte dos brasileiros ilustres, cujas biografias foram estampadas no periódico do IHGB, teria destacada a sua atuação concomitante nos negócios públicos do Império e nos serviços prestados às letras nacionais" (OLIVEIRA 2010a, p. 40). De todo modo, "no rol dos religiosos, figuras como Manoel da Nóbrega (1517-1570), Antonio Vieira (1608-1687) e José de Anchieta (1534-1597), os dois primeiros nascidos em Portugal e o último natural das Ilhas Canárias, compõem parcela significativa do corpus biográfico entre 1839 e 1849: do total de 72 biografados no período, 19 são integrantes de ordens religiosas, e igualmente considerados servidores da nação" (OLIVEIRA 2007, p. 168).
} 
Não seria fortuito que, no Brasil oitocentista, os homens de letras e de ciência compartilhassem os espaços institucionais dedicados à tarefa de inquirir o passado nacional. Nesse contexto, nas palavras de Temístocles Cezar, "nem sempre ser poeta ou romancista era incompatível com ser historiador; e ir de um gênero ao outro era uma opção, não uma impossibilidade intelectual". No entanto, tornava-se evidente a consolidação de um ethos que, de modo mais específico, definia aqueles que se dedicavam à escrita da história. Nesse caso, conforme demonstrou Rodrigo Turin, uma tríade de atributos característicos da figura do historiador - a sinceridade, a cientificidade e a utilidade - delineavam a prática historiográfica em seus vínculos mais diretos com o projeto de nação que se buscava instaurar (OLIVEIRA 2010a, p. 47).

As apropriações do estilo historiográfico presentes nas biografias eclesiásticas não são feitas pelo simples gosto ou pela pretensão de contribuir para um projeto historiográfico. Sua intenção é a de propagar e consolidar a memória de sacerdotes virtuosos, às vezes considerados santos, servindo como material de edificação e difusão da fé, sobretudo no contexto do pós-1890, com a separação entre Estado e Igreja. As biografias católicas começaram a se multiplicar na primeira metade do século XX não por acaso. Os exemplos eram para ser imitados, voltados para a consolidação de uma identidade que a Igreja Católica buscava reforçar. Nessa perspectiva, a escrita biográfica eclesiástica do oitocentos, e mesmo a do início do século $\mathrm{XX}$, apropriou-se do estilo narrativo e de algumas concepções do projeto historiográfico do IHGB, como a história mestra da vida e a escrita de biografias de "homens ilustres", porém ilustres 222 para a hierarquia eclesiástica.

Na virada do século XIX para o XX, a historiografia brasileira deixou de eleger grandes personalidades da elite brasileira para se preocupar com a "cor local", com os regionalismos, como fez Capistrano de Abreu ao estudar o sertão. Há uma mudança da noção de objetividade e imparcialidade, sendo a proximidade identitária do historiador com o objeto algo que não prejudica o trabalho histórico (ANHEZINI 2005, p. 476-477). Diferentemente da noção historiográfica das biografias do IHGB, rompia-se com a noção da história mestra da vida:

\footnotetext{
Esses textos responderam a uma série de interpretações que também concebiam o passado como referente. No entanto, esses estudos referiamse a um passado que não mais interessava ao presente, não trataram do passado que permaneceu preservado nos vestígios que naquele momento se descobriram e ganharam relevância (ANHEZINI 2005, p. 481).
}

Tais noções começaram a abrir caminho para uma escrita moderna da história que assumiria sua forma mais visível no ensaísmo das décadas de 1920 e 1930. O passado deveria ser eliminado e, a partir da escrita histórica do presente, deveria se projetar para o futuro um Brasil que até então não havia dado certo, vide o desencantamento dos autores com o sistema republicano (NICOLAZZI 2008, p. 30; 340). Em meio a tais regimes de historicidade, podemos dizer que as biografias eclesiásticas que analisamos se apropriaram de elementos da prática historiográfica das biografias do IHGB no oitocentos e 
das noções de imparcialidade e verdade que se desdobraram na historiografia do início do século XX. Apesar de almejar reforçar uma identidade religiosa até então não muito recorrente no país, a Igreja não abandonou por completo o passado em busca de modelos novos a serem construídos. Dessa forma, o diálogo com uma escrita moderna é mais tensional para o catolicismo, graças à sua ampla ligação com o passado e com a tradição.

\section{Considerações finais}

Os estilos narrativos mencionados anteriormente (hagio-biografias, biografias eclesiásticas e laicas, hagiografias) mantêm entre si uma rede de apropriações e aproximações, inclusive com o gênero historiográfico. As biografias católicas assumiam os traços heroicos e exemplares das hagiografias, fundamentando a vida de suas personagens em um viés providencialista. Todavia, incorporavam também as tensões da vida cotidiana presentes nas biografias laicas modernas surgidas a partir do século XVIII, como as Confissões de Rousseau, na qual a trajetória individual do "homem comum" era valorizada e apreciada. Entretanto, essas não eram as únicas referências.

O diálogo das biografias católicas com a cultura historiográfica de fins do século XIX e início do XX não almejava contribuir diretamente com o saber histórico promovido por instituições como o IHGB. O discurso historiográfico (assim como os seus métodos) servia como instrumento de legitimidade para as biografias católicas. A intenção de construir e divulgar "uma verdade" sobre personalidades exemplares do clero e sobre a memória da instituição fazia com que os biógrafos eclesiásticos se inspirassem nos procedimentos (ainda que retóricos) da cultura histórica da época, com destaque para os conceitos de "objetividade", "verdade", "imparcialidade" e "fontes/documentos".

O discurso histórico era apropriado de maneira singular e manuseado a fim de que os escritos biográficos católicos assumissem um tom de "verdade", contrapondo-se aos antigos estilos narrativos das hagiografias, das memórias e da ficção literária. Aproximar as biografias eclesiásticas do gênero hagiográfico ou literário poderia ser perigoso para uma conjuntura em que o discurso histórico se consolidava como promotor da identidade nacional, das "cores" regionais e de outros projetos políticos da nação.

\section{Referências bibliográficas}

ANHEZINI, Karina. Como se escreveu a história do Brasil nas primeiras décadas do século XX. Varia Historia, v. 21, n. 34, p. 476-477, Julho 2005.

CALLIGARIS, Contardo. Verdades de autobiografias e diários íntimos. Estudos Históricos, n. 21, 1998.

CERTEAU, Michel de. A invenção do cotidiano: artes de fazer. 3. ed. Petrópolis: Editora Vozes, 1998.

CEZAR, Temístocles. Livros de Plutarco: biografia e escrita da história no Brasil do século XIX. MÉTIS - história \& cultura, v. 2, n. 3, p. 73-94, 2003. 
DOSSE, François. O desafio biográfico: escrever uma vida. São Paulo: EDUSP, 2009.

HORTA, Francisco. Monsenhor Horta: esboço biográfico. São João del Rei: Oficinas Gráficas Castelo, 1934.

HORTA, José Silvério. Cartas, sermões, práticas e outros escritos. Compilados por Francisco Horta. Belo Horizonte: Imprensa Oficial do Estado de Minas, 1939.

HORTA, Monsenhor José Silvério. Manuscrito autobiográfico (Arquivo Eclesiástico da Arquidiocese de Mariana), 1932.

LEWGOY, Bernardo. A transnacionalização do espiritismo kardecista brasileiro: uma discussão inicial. Religião e Sociedade, v. 28, n. 1, p. 84-104, 2008.

MICELI, Sergio. A elite eclesiástica brasileira. São Paulo: Companhia das Letras, 2009.

NICOLAZZI, Fernando. Um estilo de história: a viagem, a memória, o ensaio. Sobre Casa-grande \& senzala e a representação do passado. Tese (Doutorado em História) - UFRGS, IFCH, Porto Alegre, 2008.

OLIVEIRA, Gustavo de Souza. Entre o rígido e o flexível: D. Antônio Ferreira Viçoso e a reforma do clero mineiro (1844-1875). Dissertação (Mestrado

Q 1 em História). Programa de Pós-Graduação em História, Universidade Estadual de Campinas, Campinas, 2010.

OLIVEIRA, Maria da Glória de. Fazer história, escrever a história: sobre as figurações do historiador no Brasil oitocentista. Revista Brasileira de História, v. 30, n. 59, p. 37-52, 2010 a.

OLIVEIRA, Maria da Glória de. Traçando vidas de brasileiros distintos com escrupulosa exatidão: biografia, erudição e escrita da história na Revista do Instituto Histórico e Geográfico Brasileiro (1839-1850). História, v. 26, n. 1, p. 154-178, 2007.

PIMENTA, Silvério Gomes, padre. Vida de D. Antonio Ferreira Viçoso. Bispo de Mariana, Conde da Conceição. 3. ed. revista pelo autor. Mariana: Typographia Archiepiscopal, 1920 [1876].

ROSA, Maria de Lurdes. "Fazer história"... para "fazer santos": uma impossível compatibilidade. Lusitania Sacra, 2a série, n. 12, p. 439-441, 2000.

SOUZA, D. Joaquim Silvério de Souza (10 Arcebispo de Diamantina). Vida de D. Silvério Gomes Pimenta, $1^{\circ}$ Arcebispo de Mariana. Editada pelo Exmo. Sr. Dom Helvécio Gomes de Oliveira. São Paulo: Escolas Profissionais do Lyceu Coração de Jesus. Alm. Barão de Piracicaba, 36-A, 1927.

VAUCHEZ, André. Santidade. In: Enciclopédia Einaudi, v. 12. Lisboa: Imprensa Nacional - Casa da Moeda, 1987. 